Nadira A Hatim

BDS, MSc (Assist Prof)

Monia MN Kandil

BDS, MSc (Assist Lect)

Elham Kh Al-Jamas

BDS, MSc, PhD (Prof)

\section{Mental Health Assessment: A Comp- arison between Different Completely Edentulous and Dentate Patients.}

\author{
Department of Prosthetic Dentistry \\ College of Dentistry, University of Mosul
}

Department of Psychology

College of Medicine, University of Mosul

\begin{abstract}
Aims: To aid the dentist, in a more precise method for the mental health assessment of edentulous patients, and isolates those who refuse complete denture wearing for psychological reasons. Materials and methods: The study was conducted during the period from July 2004 to November 2005. One hundred members with especial criteria were agreed to participate in this study. They were collected randomly from Dental College of Mosul University and Dental Health Center at Mosul city. The members were asked to answer the Mental Health Questionnaires. Results: It was found that mental health score decreased with females especially who refused the prosthodontic treatment, also groups with low educational and financial levels at same group. Members that received their prosthodontic treatment at the Dental Collage with age between (55-64) years old seamed to be achieved a highest level within the Mental Health Scale. Finally the members with high anxiety tendency, showed less mental health scores. Conclusions: The completely edentulous who refused the prosthodontic treatment, especially females, low educational and financial groups achieved the minimum scores with Mental Health Scale.

Key words: Mental health, Edentulous, Complete denture.
\end{abstract}

Hatim NA, Kandil MMN, Al-Jamas EKh. Mental Health Assessment: A Comparison between Different Completely Edentulous and Dentate Patients. Al-Rafidain Dent J. 2008; 8(2): 161-167.

Received: $15 / 7 / 2007 \quad$ Sent to Referees: $15 / 7 / 2007$

Accepted for Publication: 24/9/2007

\section{INTRODUCTION}

Mental health is fundamental to overall health and productivity. It is the basis for successful contributions to family, community, and society throughout the life span. The stigma surrounding mental illness is a powerful barrier to reaching treatment. People with mental illness feel shame and fear of discrimination about a condition that is as real and disabling as any other serious health condition. ${ }^{(1)}$

Emotional well-being and mental health concerns are major health issues in their own right. But they can also greatly affect physical health. Stress, depression, and anxiety can contribute to a host of physical ailments including digestive disorders, sleep disturbances, and lack of energy. ${ }^{(2-4)}$

Previous research suggests that mental health problems were very frequ- ent, and affect perceiving dental needs. There were also problems in obtaining full medical histories, from such sample. ${ }^{(5)}$

A significant proportion of the elderly population lives in nursing homes and suffers from varying degrees of dementia. Dementia might affect an individual's ability to implement oral care. ${ }^{(6)}$

Denture wearing and edentulism are common in older patients and can be related to poor quality of life and risk for undiagnosed oral disease and may be a marker for other medical comobilities. ${ }^{(7)}$

Aims of this study: The study designed to aid dentist in a more precise method for the mental health assessment of edentulous patients, and isolates those who refuse complete denture wearing for psychological reasons, according to some demographic variables. 


\section{MATERIALS AND METHODS}

One hundred seventy five patients diagnosed during the research period, using the basic method of dental examination. (8) They have been invited to participate at this research, and they were suitable for the criteria of the study, but only one hundred members were continued until completing the course and questionnaires, and then included in the static analysis .

The sample was divided according to the edentulous state for two groups: The first was dentate group (25 in number); The members (male or female) were taken with age 20-60 years of old, without previous serious dental problems, fit medically, and no somatic and Psychiatric abnormality (that supported by the opinion of a professional assessment-psychiatric supervisor). The second group was the completely edentulous group (75 in number) with age 50-85 years (They were completely edentulous from about three months at least) also controlled medically and physically with no somatic and/or psychiatric abnormalities, then they sub grouped divisions, each consists of 25 members:

The first subgroup was related to completely edentulous members that undergo to a prosthodontic treatment under certain circumstances, and collected from the College of Dentistry/ Mosul University, while the second subgroup was collected from the Educational Health Centre for Dentistry at Mosul City. Third subgroup of completely edentulous was collected from Mosul community and refused the prosthodontic treatment for different reasons.

Each one of the groups above classified according to sex, age, educational, anxiety and financial states; to facilitate the comparison between the members of study.

The questionnaire used at this study was the Mental health Scale: Minisota scale with multi-sides test (MMPI), which is a psychological scale, is used in different psychological purposes, as well as other medical related problem, for example; it can be used as an informal questionnaire for assessment the prosthodontic rehabilitation process. ${ }^{(9)}$
This inventory was not specified to Arab society. A modification for it had done to give us the final view of the test designed by Sa'eed $\mathrm{YN}^{(10)}$, to stabilize the measuring of mental health of Iraqi community, which had 20 components with 79 items, that include:

Person feelings with security, ability of individual to know himself correctly, the ability of individual to sense and accept himself as it is, accomplished facts in sightings, satisfaction (saturation) of the individual designers with a sanctioned manner and avoidance of in ordination, having reasonable aims in life, the ability of person to have an aim of modifications as well as seeking for anoble targets, learn from previous experiences, the rational perception of reality, mentality flexibility, ability to have public relations and friendship connections, sense of responsibility toward others, the degree of independency, espousal a definitive frame work (standardized philosophy), feeling with happiness and desirer with life, self control (especially at hard situations), bearing the responsibility of individual's actions and hid deeds, feeling with energy and activity, having a psycho - somatic health, and the reliance of individual's himself to face the daily problems and give suitable solutions for them.

The items of type statements style are prepared in a graded alternative manner, to answer with (always, often, sometimes, rarely or no). ${ }^{(11)}$

The relaxation ways and methods used especially for the group of patients that were collected from the College of Dentistry/ Mosul University; include: Simple, comfortable furniture at the clinic room. Avoid noise, crowds, uncomfortable views, and tension by talking with the patient; also help the patient to listen for soft music. Put some educated journals and scientific magazines for the patients to read during their waiting time.

Make sure that all steps of the prosthodontic treatment were carefully explained according to educational level, avoid long - time waiting visits.

After construction of the complete dentures by conventional ways ${ }^{(8,12-15)}$, and under the supervision of the Prosthetics Professors. Adjustment appointments 
(after the delivary day in about 3-5 days, each week during the first month, and recall visits interval every 1-2 months) were given to ensure the effectiveness, function and comfortability of the denturees. Totally the time spend connecting with patients after receiving their dentures was about 5-15 months.

\section{RESULTS AND DISCUSSION}

A lot of research work has been investigated the effect of tooth loss on the people's feelings ${ }^{(16,17)}$; for such importance, a needing for psycho-dental researc-hes would appeared.

The 100 members that were accepted to be involved in this study were subdivided according to their edentulous state and denture instruction experience to four groups. Then they asked to answer the "Mental health Questionnairs" to evaluate their mental health, according to different demographic variables.
The members of each group were arithmetic in numbers with the others as a result of random chosen of the samples, and tried to close the number of members within the demographic variable groups.

The members of this group had different reasons and period of edentulism, to represent the general complete denture wearer population.

With the sex variable: Males generally showed no significant variation in mental health scale between their groups. A significancy was obtained between females undergoing prosthodontic treatment, which they had the highest score, but in case of females who refused the prosthodontic treatment, they had the lowest value of mental health scale, Table (1). Myers ${ }^{(18)}$ opinion, who studied the relationship of the women irritable personality, that this related to psycho-somatic pressures, and he believed that happiness associated to social support, marriage, career and religious faith, can play an effective role in general and mental health.

Table (1): Multiple Duncan's Range; according to sex variation, within the Mental Health Scale.

\begin{tabular}{ccccc}
\hline Groups & Sex & Number & $* *$ Mean \pm SE & $\begin{array}{c}\text { Duncan's } \\
\text { group* }\end{array}$ \\
\hline $\begin{array}{c}\text { Complete edentulous who included in treatment } \\
\text { course at Mosul, college of dentistry }\end{array}$ & Male & 19 & $71.765 \pm 2.055$ & $\mathrm{AB}$ \\
Complete edentulous who included in treatment & Female & 6 & $74.894 \pm 2.204$ & $\mathrm{~A}$ \\
course at Mosul, health center & Male & 17 & $72.836 \pm 1.788$ & $\mathrm{AB}$ \\
Complete edentulous who refused the & Female & 8 & $73.386 \pm 3.155$ & $\mathrm{AB}$ \\
prosthodontic treatment & Male & 17 & $69.650 \pm 1.465$ & $\mathrm{AB}$ \\
Members who have complete dentition & Female & 8 & $59.177 \pm 4.253$ & $\mathrm{C}$ \\
& Male & 16 & $71.376 \pm 1.849$ & $\mathrm{AB}$ \\
& Female & 9 & $70.773 \pm 2.815$ & $\mathrm{AB}$ \\
\hline
\end{tabular}

* Different letters vertically: significant difference at $p \leq 0.05 ; * *$ Mean: mean of Mental Health Scale measure.

The educational levels variable: Within Table (2), only the completely edentulous that refused treatment with low education (can't read or write) were significantly differ from other groups. This is proved and discussed also with a study done by Čelebić et al., ${ }^{(19)}$ concluded that the level of education, had relation with the satisfaction and acception of the complete denture, because the ignore pers- on couldn't assess his condition in a suitable manner.

At Table (3) which included the financial levels (money income) variable, proved: The financial state plays an effective role in the mental health and psychological state of peoples, this conclusion had the same direction with researches done by Belle et al.; Allen and McMillan, they stated that patients with higher socioeconomic status were more 
likely to accept complete dentures, than with the low levels. ${ }^{(20,21)}$

If a comparison was done only for the completely edentulous groups, the result showed that the group with an age between fifty five and sixty four years of old that received treatment at Dentistry College at Mosul University, had the highest score within Mental Health Scale= 81.329, Table (4). This was also similar to investigations done by Hagglin et al. ${ }^{(22)}$, and the opinion for such result that person at this age become a mature and wise mentally than other ages.

Within the anxiety level variable, the groups generally tend to be more neurotic in behavior were more anxious, and less in mental health. This may due to genetic and environmental factors ${ }^{(23)}$, the same authorities emphasize the role played by an adverse environment. In particular, high levels of conflict and criticism combined with low levels of sympathy, this describedvat Table (5).

Table (2): Multiple Duncan's Range; according to Education variation, within Mental Health Scale.

\begin{tabular}{ccccc}
\hline Groups & Education Number & $* *$ Mean \pm SE & $\begin{array}{c}\text { *Duncan's } \\
\text { group }\end{array}$ \\
\hline $\begin{array}{c}\text { Complete edentulous who included in } \\
\text { treatment course at Mosul, college of dentistry }\end{array}$ & Low & 12 & $69.008 \pm 1.647$ & $\mathrm{~A}$ \\
Complete edentulous who included in treatment & Low & 13 & $75.754 \pm 2.523$ & $\mathrm{~A}$ \\
$\begin{array}{c}\text { course at Mosul, health center } \\
\text { Complete edentulous who refused the }\end{array}$ & High & 11 & $73.325 \pm 2.393$ & $\mathrm{~A}$ \\
prosthodontic treatment & Low & 12 & $62.766 \pm 2.093$ & $\mathrm{~A}$ \\
Members who have complete dentition & Low & 13 & $70.009 \pm 1.957$ & $\mathrm{~A}$ \\
& High & 15 & $72.455 \pm 2.183$ & $\mathrm{~A}$ \\
\hline
\end{tabular}

*Different letters vertically: significant difference at $p \leq 0.05 ; * *$ Mean: mean of Mental Health Scale measure

Table (3): Multiple Duncan's Range; according to financial variation, within the Mental Health Scale.

\begin{tabular}{ccccc}
\hline Groups & Finances & Number & $* *$ Mean \pm SE & $\begin{array}{c}\text { *Duncan's } \\
\text { group }\end{array}$ \\
\hline $\begin{array}{c}\text { Complete edentulous who included in treatment } \\
\text { course at Mosul, college of dentistry }\end{array}$ & Low & 9 & $69.704 \pm 1.728$ & $\mathrm{~A}$ \\
& Medium & 10 & $75.468 \pm 3.079$ & $\mathrm{~A}$ \\
& High & 6 & $71.814 \pm 3.678$ & $\mathrm{~A}$ \\
Complete edentulous who included in treatment & Low & 9 & $73.136 \pm 2.874$ & $\mathrm{~A}$ \\
course at Mosul, health center & Medium & 8 & $72.594 \pm 2.364$ & $\mathrm{~A}$ \\
& High & 8 & $73.291 \pm 3.044$ & $\mathrm{~A}$ \\
Complete edentulous who refused the & Low & 9 & $61.012 \pm 4.000$ & $\mathrm{~B}$ \\
prosthodontic treatment & Medium & 9 & $69.507 \pm 0.899$ & $\mathrm{~A}$ \\
& High & 6 & $69.957 \pm 4.277$ & $\mathrm{~A}$ \\
Members who have complete dentition & Low & 6 & $69.746 \pm 3.018$ & $\mathrm{~A}$ \\
& Medium & 6 & $66.708 \pm 3.186$ & $\mathrm{AB}$ \\
& High & 13 & $73.865 \pm 1.943$ & $\mathrm{~A}$ \\
\hline
\end{tabular}

*Different letters vertically: significant difference at $p \leq 0.05 ; * *$ Mean: mean of Mental Health Scale measure. 
Table (4): Multiple Duncan's Range; according to Age variation, within the Mental Health Scale.

\begin{tabular}{ccccc}
\hline Groups & Age group & Number & $* *$ Mean \pm SE & $\begin{array}{c}* \text { Duncan's } \\
\text { group }\end{array}$ \\
\hline Complete edentulous who included in & $\leq 54$ & 9 & $68.016 \pm 2.644$ & CDEF \\
treatment course at Mosul, college of & $55-64$ & 4 & $81.329 \pm 3.963$ & AB \\
dentistry & $65-74$ & 8 & $75.537 \pm 1.249$ & ABCD \\
& $\geq 75$ & 4 & $67.784 \pm 4.094$ & CDEF \\
Complete edentulous who included in & $55-64$ & 12 & $73.396 \pm 2.042$ & ABCD \\
treatment course at Mosul, health center & $65-74$ & 5 & $73.974 \pm 4.384$ & ABCD \\
& $\geq 75$ & 3 & $70.632 \pm 5.334$ & BCDE \\
Complete edentulous who refused the & $55-64$ & 9 & $70.970 \pm 1.893$ & BCDE \\
prosthodontic treatment & $65-74$ & 10 & $66.962 \pm 3.294$ & DEF \\
& $\geq 75$ & 4 & $58.354 \pm 3.031$ & F \\
& $\leq 34$ & 12 & $69.535 \pm 2.611$ & BCDEF \\
Members who have complete dentition & $35-44$ & 6 & $69.156 \pm 1.828$ & CDEF \\
& $45-54$ & 3 & $70.886 \pm 3.480$ & BCDE \\
& $\geq 55$ & 4 & $79.240 \pm 0.516$ & ABC \\
\hline
\end{tabular}

*Different letters vertically: significant difference at $p \leq 0.05$; ${ }^{*}$ Mean: mean of Mental Health Scale measure.

Table (5): Multiple Duncan's Range; according to Anxiety level variation, within the Mental Health Scale.

\begin{tabular}{|c|c|c|c|c|}
\hline Groups & Anxiety & Number & $* *$ Mean \pm SE & $\begin{array}{c}\text { *Duncan's } \\
\text { group }\end{array}$ \\
\hline \multirow{4}{*}{$\begin{array}{l}\text { Complete edentulous who included in } \\
\text { treatment course at Mosul, college of } \\
\text { dentistry }\end{array}$} & Low & 18 & $74.739 \pm 1.747$ & $\mathrm{~A}$ \\
\hline & Medium & 4 & $61.708 \pm 2.151$ & $\mathrm{BCD}$ \\
\hline & High & 3 & $73.586 \pm 3.801$ & $\mathrm{AB}$ \\
\hline & Low & 17 & $73.909 \pm 1.936$ & $\mathrm{AB}$ \\
\hline \multirow{3}{*}{$\begin{array}{l}\text { Complete edentulous who included in } \\
\text { treatment course at Mosul, health center }\end{array}$} & Medium & 5 & $70.835 \pm 3.933$ & $\mathrm{AB}$ \\
\hline & High & 3 & $71.561 \pm 2.797$ & $\mathrm{AB}$ \\
\hline & Low & 15 & $68.084 \pm 2.373$ & $\mathrm{ABC}$ \\
\hline \multirow{2}{*}{$\begin{array}{l}\text { Complete edentulous who refused the } \\
\text { prosthodontic treatment }\end{array}$} & Medium & 5 & $70.025 \pm 1.223$ & $\mathrm{AB}$ \\
\hline & High & 5 & $57.215 \pm 4.751$ & $\mathrm{CD}$ \\
\hline \multirow{2}{*}{ Members who have complete dentition } & Low & 24 & $71.909 \pm 1.383$ & $\mathrm{AB}$ \\
\hline & Medium & 1 & $53.164 \pm 0.000$ & $\mathrm{D}$ \\
\hline
\end{tabular}




\section{CONCLUSION}

Mental Health Scale for females that refused the prosthodontic treatment, showed a reduction in values, also with low educational and financial levels for same group. In some manners the members with high anxiety tendency, showed less mental health scores .

\section{REFERENCES}

1. David Satcher. MENTAL HEALTH: CULTURE, RACE, AND ETHNICITY: (A Report of the Surgeon General; U.S. Public Health Service). DEPARTMENT OF HEALTH AND HUMAN SERVICES (U.S. Public Health Service) 1999; http://mentalhealth.samhsa.gov/cre/preface asp

2. Harvard Medical School Emotional \& Mental Health Information. Up to date insight on emotional health conditions \& mental health problems. Harvard Medical School Publications website. at 2007; http://www.health.harvard.edu/Emotional Well Being and Mental Health/

3. Zaff JF, Calkins J. Background for Community-Level Work on Mental Hea1th and Externalizing Disorders in Adolescence: Child Trends. Washington, D.C.; Publications may also be ordered from Child Trends' Web site, at 2001. www.childtrends.org.

4. Bridges LJ, Geyelin Margie N and Zaff J. Background for Community-Level Work on Emotional Well-being in Adolescence: Child Trends. Washington, D.C.; Publications may also be ordered from Child Trends' Web site, www.childtrends.org. at 2002.

5. Waplington J, Morris J. The dental needs, demands and attitudes of a group of homeless people with mental health problems. Community Dent Health. 2000; 17: 134-137.

6. Adam H, Antony J. The oral health of individuals with dementia in nursing homes Preston. Gerodontology. 2006; 23: 99105.

7. Robert J. Weyant, Rajesh S. Pandav, Judith L. Plowman and Mary Ganguli. Medical and Cognitive Correlates of Denture Wearing in Older CommunityDwelling Adults. AGS, 2004; 52: 596.

8. Zarb GA, Bolender CL, Carlsson GE
(1997) Boucher's Prosthodontic Treatment for Edentulous Patients. $11^{\text {th }}$ ed. Mosby, Inc. 1997; Pp: 57-78.

9. Hall ML, Hazen SP, Moyers RE, Redig DF, Robinson HG, Silverman SI. Psychologic Factors Involved in Maxillofacial Prosthesis. Year Book Medical Publishers. 1980; Pp: 209-210.

10. Sa'eed YN. Constructing a scale of Mental Health for University Students According to Indicators of MinnesotaMutiphasic Personality Inventory M.M.P.I. Ph.D. thesis, College of Education, Ibn Rushd, Baghdad University. 2003.

11. Kandil MN. Psychological Assessment of the Patient pre and post the Prosthodontic Treatment. M.Sc. thesis, College of Dentistry, Mosul University. 2006.

12. Sowter HB. Dental Laboratory Technology Prosthodontic Techniques. University of North Carolina in United States of America. 1968.

13. Sellen PN, Jagger DC, Harrison A.. An assessment of the ability of dental undergraduates to choose artificial teeth which are appropriate for the age and sex of the denture wearer: a pilot study. J Oral Rehabilit. 2001; 28: 958-61.

14. Heasman P. Master Dentistry: Restorative Dentistry, Pediatric Dentistry and Orthodontics. Churchill Livingstone. 2003; P: 125.

15. Pound E. Utilizing Speech to Simplify a Personalized Denture Service. J Prosthet Dent. 2006; 95(1): 1-9.

16. Fiske J, Davis DM, Frances C, Gelbier S. The emotional effects of tooth loss in edentulous people. Br Dent J. 1998; 184: 90-3.

17. Davis DM, Fiske J, Scott B, Radford DR .The emotional effects of tooth loss: a preliminary quantitative study. Br Dent $J$. 2000; 188: 503-8.

18. Myers DG. The Funds, Friends, and Faith of Happy People. American Psychologist. 2000; 55(1): 56-67.

19. Čelebić A, Knezoić-Zlatarić D, Papić M, Carek V, Baučić I, Stipetić J. Factors Related to Patient Satisfaction With Complete Denture Therapy. J Gerontol. 2003; 58A (10): 948-53.

20. Belle D, Doucet J, Harris J, Miller J, Tan E. Who Is Rich? Who Is Happy? American Psychologist. 2000; 55(10): 1160. 
21. Allen PF, McMillan AS. A Review of the Functional and Psychosocial Outcomes of Edentulousness Treated with Complete Replacement Dentures. J Can Dent Assoc. 2003; 69(10): 662.

22. Hagglin C, Hakeberg $M$, Ahlqwist $M$, Sullivan M, Berggren U. Factors associated with dental anxiety and attendance in middle-aged and elderly women.
Community Dent Oral Epidemiol. 2000; 28(6): 451-60.

23. Ge $\mathrm{X}$, Conger RD, Cadoret RJ, Neiderhiser JM, Yates W. The developpmental interface between nature and nurture: a mutual influence model of child antisocial behavior and parent behaviors. Devel Psych. 1996; 32:574-89. 